\title{
Characteristics of Triatomine infestation and natural Trypanosoma cruzi infection in the State of Rio Grande do Norte, Brazil
}

\author{
Andressa Noronha Barbosa-Silva ${ }^{[1],[2],}$ Antonia Cláudia Jácome da Câmara ${ }^{[1],[3],}$ \\ Kiev Martins ${ }^{[1]}$, Daniela Ferreira Nunes ${ }^{[2]}$, Pedro Igor Câmara de Oliveira ${ }^{[1]}$, \\ Paulo Roberto Medeiros de Azevedo ${ }^{[4]}$, Egler Chiari ${ }^{[2]}$ \\ and Lúcia Maria da Cunha Galvão ${ }^{[1],[2]}$
}

[1]. Programa de Pós-Graduação em Ciências Farmacêuticas, Centro de Ciências da Saúde, Universidade Federal do Rio Grande do Norte, Natal, Rio Grande do Norte, Brasil. [2]. Programa de Pós-Graduação em Parasitologia, Departamento de Parasitologia, Instituto de Ciências Biológicas, Universidade Federal de Minas Gerais, Belo Horizonte, Minas Gerais, Brasil. [3]. Departamento de Análises Clínicas e Toxicológicas, Centro de Ciências da Saúde, Universidade Federal do Rio Grande do Norte, Natal, Rio Grande do Norte, Brasil. [4]. Departamento de Estatística, Centro de Ciências Exatas e da Terra, Universidade Federal do Rio Grande do Norte, Natal, Rio Grande do Norte, Brasil.

\begin{abstract}
Introduction: Natural and artificial ecotope infestation by the kissing bug triatomines and their colonization and infection by Trypanosoma cruzi, the Chagas disease agent, were evaluated in nine municipalities of the State of Rio Grande do Norte, Brazil. Methods: Following identification, triatomine intestinal contents were analyzed by direct microscopic examination, xenoculture, and polymerase chain reaction (PCR) for parasite detection. Trypanosoma cruzi isolates were genotyped using three different markers. Results: Of 842 triatomines captured, 65\% were Triatoma brasiliensis, 17.8\% Triatoma pseudomaculata, 12.5\% Panstrongylus lutzi, and $4.7 \%$ Rhodnius nasutus. Triatoma brasiliensis and $P$. lutzi adults were found in the intradomicile. T. brasiliensis, T. pseudomaculata, and R. nasutus nymphs and adults were found in the peridomicile and wild environment. Intradomiciliary and peridomiciliary infestation indexes were $5.6 \%$ and $33.7 \%$, respectively. In the peridomicile, chicken coops were the most infested ecotope. The T. cruzi triatomine infection rate was 30.2\%, of which PCR detected $29 \%$. P. lutzi (78.1\%), T. brasiliensis (24.5\%), and T. pseudomaculata $(22.7 \%)$ were the most infected species. TcII and III genotypes were detected in T. brasiliensis and TcIII in P. lutzi. Conclusions: T. brasiliensis was found in all environments and most ecotopes with high T. cruzi infection rates. High infection rates were also detected in T. pseudomaculata and $P$. lutzi, suggesting their role in the interchange between the wild and peridomestic transmission cycles. The combination of PCR, microscopic examination, and xenoculture contributed to improving T. cruzi infection evaluation in triatomine bugs. The TcII and TcIII genotypes were predominant in the study area.
\end{abstract}

Keywords: Trypanosoma cruzi. Triatominae natural infection. PCR. Xenoculture. Direct microscopic examination.

\section{INTRODUCTION}

Trypanosoma cruzi is the etiological agent of Chagas disease, and its main vectors belong to the genera Panstrongylus, Rhodnius, and Triatoma. Among these blood-sucking reduviid bugs of the subfamily Triatominae, 70 of the over 148 Triatominae species described ${ }^{(1)}$ are naturally infected by $T$. cruzi $^{(2)}$. Infection is maintained primarily within three overlapping cycles: domiciliary, peridomiciliary, and sylvatic ${ }^{(3)}$. Vector transmission remains the most important route of parasite to human transmission owing to the natural distribution of $T$. cruzi in the triatomine species adapted to domestic or

Corresponding author: Dra. Lúcia Maria C. Galvão.

e-mail: galvao@icb.ufmg.br

Received 29 August 2015

Accepted 28 January 2016 peridomestic environments; this adaptation to human dwellings strongly determines human infection rates ${ }^{(4)}$.

The Brazilian Northeast, one of the poorest and most underdeveloped regions within Brazil, is considered the most important region therein for American trypanosomiasis, where native species like Triatoma brasiliensis Neiva, 1911, Triatoma pseudomaculata Corrêa and Espínola, 1964, Panstrongylus lutzi Neiva \& Pinto, 1926, and Rhodnius nasutus Stal, 1859 are widespread ${ }^{(5)(6)}$. Triatoma brasiliensis is distributed in nine Northeast states, Tocantins, and Minas Gerais ${ }^{(7)}$. Considered the main vector of $T$. cruzi in the Northeastern semiarid regions, it colonizes both sylvatic and domestic environments but is more frequently captured in peridomestic areas ${ }^{(5)(8)(9)(10)(11)}$. Triatomine control remains problematic as this region is the center of dispersion and has higher T. brasiliensis concentrations ${ }^{(12)(13)(14)}$; it is further aggravated by local vector control activity discontinuation and wild and domestic environmental overlap ${ }^{(15)(16)(17)}$. Triatoma pseudomaculata also demonstrates high domiciliation capacity, 
thereby increasing its colonization rate in several states $^{(5)(18)}$; such native triatomines that sporadically invade or reinvade human dwellings further complicate vector control consolidation $^{(18)}$.

Triatomines can be infected with several flagellates and T. cruzi infection level evaluation in wild, peridomiciliary, and domiciliary environments has relevance for control programs aimed at reducing human infections ${ }^{(19)(20)}$. Trypanosoma cruzi has been detected in the excreta or intestinal contents of triatomines by direct microscopic examination (DME) ${ }^{(19)(21)}$, necessitating the ability to distinguish this protozoan from other trypanosomatids. Although DME is reliable and relatively inexpensive, disadvantages related to sensitivity, specificity ${ }^{(22)(23)(24)}$, and poor performance on dead insects ${ }^{(25)}$ exist. Xenoculture is used for quality control to confirm negative intestinal content results ascertained by DME, whereas positive cultures allow for $T$. cruzi strain isolation ${ }^{(26)}$ pursuant to e.g. genetic studies. For detecting T. cruzi in reduviid bug feces or urine and mammalian blood samples, polymerase chain reaction (PCR) is generally superior ${ }^{\text {(21) (22) (27) }}$ and can also genotype T. cruzi using different targets.

Such methodology has increased the rate of positivity of infection in field studies, which is especially important in areas where there is scarce information on vector infection following control and surveillance programs. A recent seroepidemiological survey showed high seroprevalence for municipalities in the west and central mesoregions of the State of Rio Grande do Norte (RN) $)^{(28)}$, and genotyping studies identified T. cruzi I (TcI) in T. brasiliensis and TcIII (formerly called TcIIc) in armadillos ${ }^{(29)}$, TcI and TcII in humans, TcII and TcIII in T. brasiliensis, and TcIII in P. lutzi $i^{(15)}$.

The purpose of this study was to evaluate the occurrence of triatomine infestation of natural and artificial ecotopes, and the colonization and T. cruzi infection in triatomines collected from different environments in the west and central mesoregions of the State RN, Brazil. Diagnostic method efficacy and reproducibility were evaluated and the T. cruzi populations isolated from positive triatomines were genotyped to establish their genetic groups.

\section{METHODS}

\section{Study area}

State of Rio Grande do Norte, located in northeastern Brazil, is divided into 167 municipalities distributed in four mesoregions: West, Central, Agreste, and East. About $90 \%$ of the territory represents arid and semiarid climates, where the predominant biome is the Caatinga, characterized as containing thorny shrubs, irregular structure, and partially uncovered soil. This study was conducted in the municipalities of Apodi, Caraúbas, Governador Dix-Sept Rosado, Lucrécia, Mossoró, Severiano Melo, São Miguel, Caicó, and Serra Negra do Norte in the West and Central mesoregions (Figure 1), which were selected in reference to the seroepidemiological survey conducted between 2007 and $2009^{(28)}$.

\section{Triatomine collection and identification}

Triatomines were captured in rural areas of the nine municipalities in intradomicile, peridomicile, and wild environments from March 2009 to August 2012. The intradomiciliary environment was surveyed in 250 domiciliary units (DU) together with 187 artificial structures in the peridomicile such as chicken coops $(n=110)$, corrals $(n=25)$, pigsties $(n=2)$, piles of tiles $(n=44)$, old stone fence structures $(\mathrm{n}=2)$, and dry carnauba palm tree (Copernicia prunifera) straw $(n=4)$. Entomological indicators were used to calculate the colonization and species peridomiciliary and domiciliary infestation indices ${ }^{(30)}$.

Wild environment captures were performed in Apodi, Caraúbas, and Serra Negra do Norte in rock outcrops $(\mathrm{n}=9)$, stone fences $(\mathrm{n}=2)$, bird's nests $(\mathrm{n}=5)$, and carnauba palm trees $(n=16)$, the latter as previously described ${ }^{(31)}$.

In Serra Negra do Norte, wild triatomines capture was conducted at the Seridó Ecological Station (ESEC-Seridó)/ Instituto Chico Mendes de Conservação da Biodiversidade (ICMBio), created by Decree 87222 of $05 / 31 / 1982$, Law 6902 04.27.1982 as a Conservation Unit. Some adult insects were captured in station lodgings and were classified as an undefined ecotope. Insects were captured both day and night by the principal author with the assistance of the respective Municipal Health Secretariat technicians via manual searches using tweezers and a flashlight in all environments and without the use of insect dislodging substances, and were individually identified as described ${ }^{(32)}$.

\section{Natural infection of triatomine bugs}

Direct microscopic examination. Collected triatomines were examined individually and their intestinal content was removed under aseptic conditions and placed in a well of a 24-well plate containing $500 \mu \mathrm{L}$ sterile saline solution. After homogenization, $5 \mu \mathrm{L}$ suspension was used to identify trypanosomatid forms via DME at $400 \times$ magnification $^{(26)}$ and smear stained by Giemsa $(1,000 \times)$.

Xenoculture. Approximately $250 \mu \mathrm{L}$ intestinal content suspension was seeded in $15 \mathrm{~mL}$ tubes containing liver infusion tryptose culture medium ${ }^{(33)}$ plus McNeal Novy Niccole or blood agar and incubated at $28^{\circ} \mathrm{C}$. Aliquots were examined after 15 , 30 , and 60 days by DME $(400 \times)^{(26)}$.

PCR with species-specific primers. Deoxyribonucleic acid (DNA) was extracted via phenol-chloroform ${ }^{(34)}$ using $200 \mu \mathrm{L}$ diluted insect intestinal content solution $(\mathrm{v} / \mathrm{v})$ in $0.2 \mathrm{M}$

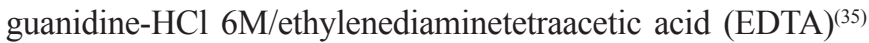
maintained for 5-7 days at room temperature and stored at $4^{\circ} \mathrm{C}$ until DNA extraction. PCR amplifications were performed in duplicate, as described ${ }^{(34)}$, using specific primers to identify T. $\mathrm{cruzi}^{(36)}$. PCR assays were performed in a DNA clean chamber to avoid contamination and positive and negative controls were used to monitor each step.

For Trypanosoma cruzi and Trypanosoma rangeli Tejera, 1920 differential diagnosis, multiplex PCR was performed 


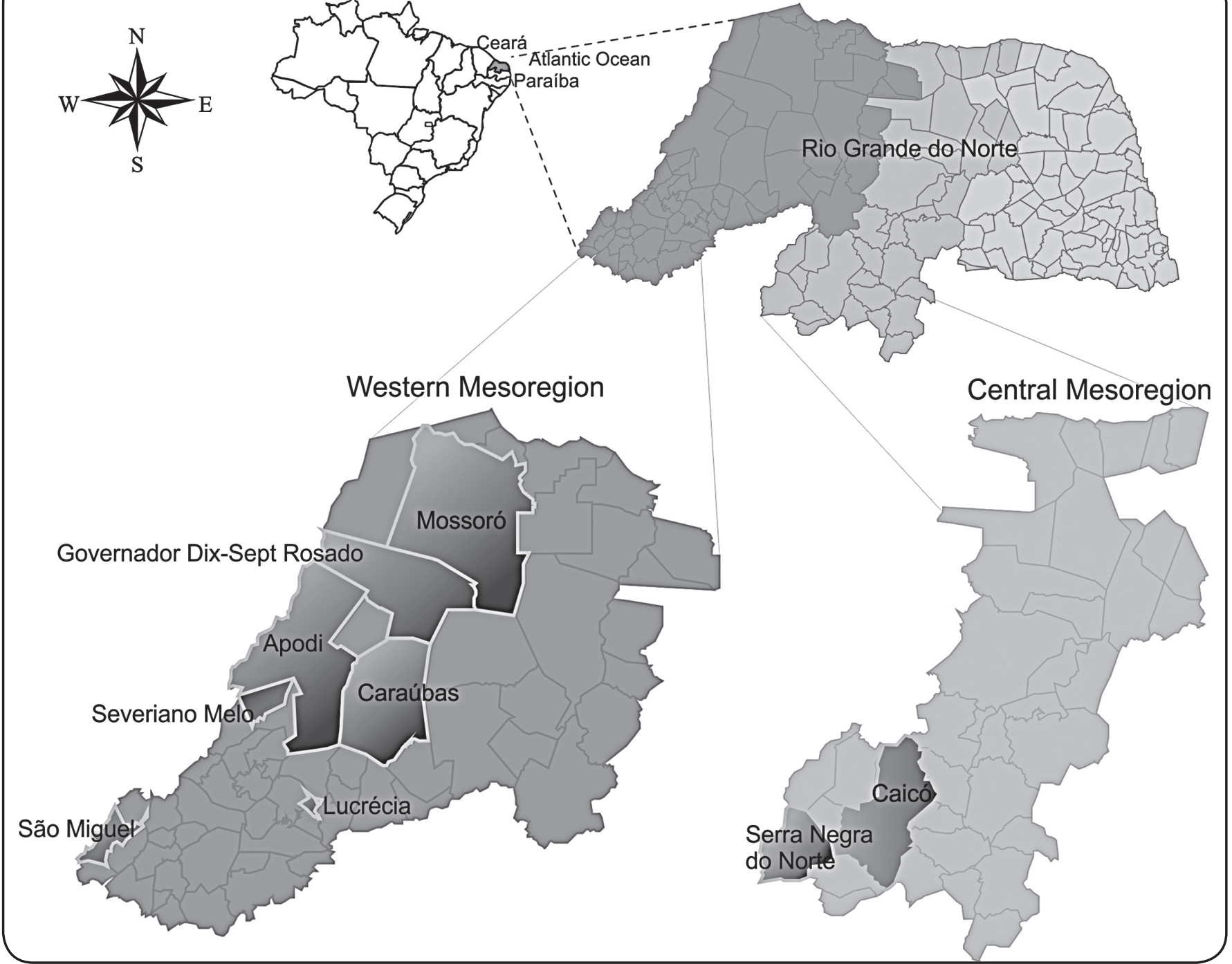

FIGURE 1 - Map of the State of Rio Grande do Norte highlighting the West and Central mesoregions. The study area showing the surveyed municipalities is shown in dark grey.

as described ${ }^{(37)}$. As positive controls, Trypanosoma cruzi cell cultures of the Colombian strains (T. cruzi I), JG (T. cruzi II), and $T$. rangeli were used.

\section{Trypanosoma cruzi isolates for genotyping}

Cultured parasite genomic DNA obtained using phenolchloroform was used as PCR assay templates ${ }^{(38)}$. Trypanosoma cruzi isolates were typed using three different parasite genomic sequences as reported ${ }^{(39)}$, with the $24 \mathrm{~S} \alpha$ ribosomal (rRNA) gene D7 domain ${ }^{(40)}$, mitochondrial cytochrome oxidase subunit 2 gene $(\mathrm{COII})^{(41)}$, and the spliced leader genes intergenic region ${ }^{(42)}$ as markers for six discrete typing units (DTUs) ${ }^{(43)}$, using T. cruzi reference strains ${ }^{(15)(44)(45)}$ and clones ${ }^{(46)(47)}$ as DTU controls.

All PCR products were analyzed by $6 \%$ polyacrylamide gel electrophoresis and visualized by silver staining ${ }^{(48)}$.

\section{Statistical analysis}

To quantify the concordance between the results of different methods, generalized Kappa (hat $k$ ) coefficients were estimated and an approximate $95 \%$ confidence interval $\left(\mathrm{CI}_{95 \%}\right)$ for $k$ [lower confidence limit (LCL) and upper confidence limit (UCL) $]^{(49)}$ was calculated and classified accordingly ${ }^{(50)}$.

\section{RESULTS}

Table 1 shows that were captured 842 triatomines including T. brasiliensis (65\%), T. pseudomaculata (17.8\%), P. lutzi (12.5\%), and R. nasutus (4.7\%). T. brasiliensis was predominant in intradomicile $(\mathrm{n}=12)$, peridomicile $(\mathrm{n}=323)$, and wild environments $(n=212)$. Table 1 shows specimen numbers per species, environment, and municipality. 
TABLE 1 - Number of triatomine bugs captured in different environments in the west and central mesoregions in nine municipalities in the State of Rio Grande do Norte, Brazil (2009-2012).

\begin{tabular}{|c|c|c|c|c|c|c|c|c|c|c|}
\hline \multirow{2}{*}{ Municipalities } & \multicolumn{8}{|c|}{ Triatomine species } & & \\
\hline & $\mathbf{n}$ & $\%$ & $\mathbf{n}$ & $\%$ & $\mathbf{n}$ & $\%$ & $\mathbf{n}$ & $\%$ & $\mathbf{n}$ & $\%$ \\
\hline \multicolumn{11}{|l|}{ Central mesoregion } \\
\hline Caicó & 23 & 4.3 & 0 & 0.0 & 0 & 0.0 & 1 & 2.5 & 24 & 2.9 \\
\hline \multicolumn{11}{|l|}{ West mesoregion } \\
\hline Apodi & 35 & 6.4 & 20 & 13.3 & 0 & 0.0 & 21 & 52.5 & 76 & 9.0 \\
\hline Caraúbas & 303 & 55.4 & 65 & 43.4 & 3 & 2.9 & 18 & 45.0 & 389 & 46.2 \\
\hline Governador Dix-Sept & 50 & 9.2 & 0 & 0.0 & 0 & 0.0 & 0 & 0.0 & 50 & 5.9 \\
\hline São Miguel & 1 & 0.1 & 12 & 8.0 & 0 & 0.0 & 0 & 0.0 & 13 & 1.5 \\
\hline Severiano Melo & 4 & 0.7 & 8 & 5.3 & 0 & 0.0 & 0 & 0.0 & 12 & 1.4 \\
\hline Total & 547 & 65.0 & 150 & 17.8 & 105 & 12.5 & 40 & 4.7 & 842 & 100.0 \\
\hline \multicolumn{11}{|l|}{ Environments Wild } \\
\hline nymphs & 89 & 42.0 & 16 & 27.5 & 0 & 0.0 & 6 & 33.3 & 111 & 28.5 \\
\hline adults & 123 & 58.0 & 42 & 72.5 & 102 & 100.0 & 12 & 66.7 & 279 & 71.5 \\
\hline \multicolumn{11}{|l|}{ Peridomicile } \\
\hline nymphs & 200 & 61.9 & 54 & 58.6 & 0 & 0.0 & 9 & 40.9 & 263 & 60.2 \\
\hline adults & 123 & 30.1 & 38 & 41.4 & 0 & 0.0 & 13 & 59.1 & 174 & 39.8 \\
\hline \multicolumn{11}{|l|}{ Intradomicile } \\
\hline
\end{tabular}

In the wild, $48.5 \%(16 / 33)$ of the ecotopes were infested by triatomines. High infestation was observed in stone fences (100\%) and rock outcrops (75\%) in Serra Negra do Norte in comparison with other ecotopes. In the peridomicile, the infestation index was 33.7\% (63/187) with T. brasiliensis and T. pseudomaculata at indices at 26.2\% (49/187) and 5.9\% $(11 / 187)$, respectively, primarily in chicken coops. The intradomicile infestation index was 5.6\%(14/250). Table 2 shows the colonization index of each ecotope by triatomine species.

All the insects were examined; $30.2 \%$ exhibited T. cruzi infection, with $P$. lutzi demonstrating the highest rates (78.1\%). The highest infection rate was detected by PCR (29\%), detecting T. cruzi infection in most $P$. lutzi (69.5\%) and T. brasiliensis (24.3\%) specimens (Figure 2A). Kappa evinced no agreement between T. cruzi detection methods for $T$. brasiliensis [hat $k=-0.0112 ; \mathrm{CI}_{95 \%}=(-0.0596$; 0.0372)], T. pseudomaculata [hat $k=0.0036 ; \mathrm{CI}_{95 \%}=(-0.0888$; $0.0960)]$, P. lutzi $\left[\right.$ hat $\left.k=0.0690 ; \mathrm{CI}_{95 \%}=(-0.0414 ; 0.1794)\right]$, and $R$. nasutus (hat $\left.k=0.1652 ; \mathrm{CI}_{95 \%}=(-0.0137 ; 0.3441)\right]$. The global infection index was $0.12\left[\mathrm{CI}_{95 \%}=(0.0773 ; 0.1553)\right]$ indicating slight methodological agreement, but significantly different from zero as excluded by the CI.
Figure 2B shows that the highest infected specimen rate $(53.3 \%)$ occurred in the intradomicile [primarily $P$. lutzi $(66.7 \%)]$, followed by the wild environment (40.5\%) and peridomicile (20.1\%) [primarily P. lutzi and T. pseudomaculata (78.4\% and $27.2 \%$, respectively)].

In the wild, T. brasiliensis presented high infection indices in Serra Negra do Norte (31.4\%) and Caraúbas (26.1\%) rock outcrops. T. cruzi infection was also detected in $R$. nasutus in carnauba palm trees. In the peridomicile, T. brasiliensis presented high infection indexes in piles of tiles $(38.1 \%)$ and corrals $(37.5 \%)$ in Governador Dix Sept Rosado and Caraúbas, respectively, and $T$. pseudomaculata in chicken coops (30.8\%) in Caraúbas (Table 2).

Intestinal contents of all infected triatomines and 100 uninfected specimens were submitted to multiplex PCR using primers for $T$. rangeli and produced no overlapping data, thus confirming that $T$. cruzi-specific amplification.

Trypanosoma cruzi DTUs were identified in 15 samples from three municipalities. We isolated 3 TcII and 3 TcIII stocks from T. brasiliensis captured in Caicó and Serra Negra do Norte, respectively,and 9 TcIII T. cruzi were isolated from P. lutzi in Caraúbas (Table 3). 
TABLE 2 - Entomological indicators observed in the ecotopes of different environments in the municipalities of the State of Rio Grande do Norte.

\begin{tabular}{|c|c|c|c|c|c|c|c|c|c|c|c|c|c|}
\hline Ecotopes & $\begin{array}{c}\text { Infested } \\
\text { ecotopes } \\
\%\end{array}$ & \multicolumn{3}{|c|}{$\begin{array}{c}\text { Triatoma } \\
\text { brasiliensis } \\
\%\end{array}$} & \multicolumn{3}{|c|}{$\begin{array}{c}\text { Triatoma } \\
\text { pseudomaculata } \\
\%\end{array}$} & \multicolumn{3}{|c|}{$\begin{array}{c}\text { Panstrongylus } \\
\text { lutzi } \\
\% \\
\end{array}$} & \multicolumn{3}{|c|}{$\begin{array}{c}\text { Rhodnius } \\
\text { nasutus } \\
\% \\
\end{array}$} \\
\hline \multicolumn{14}{|l|}{ Wild environment } \\
\hline \multicolumn{14}{|l|}{ Apodi } \\
\hline \multicolumn{14}{|l|}{ Caraúbas } \\
\hline carnauba palm trees & 42.8 & 0.0 & 0.0 & 0.0 & 0.0 & 0.0 & 0.0 & 0.0 & 0.0 & 0.0 & 42.8 & 33.3 & 16.7 \\
\hline rock outcrops & 60.0 & 60.0 & 33.3 & 26.1 & 0.0 & 0.0 & 0.0 & 0.0 & 0.0 & 0.0 & 0.0 & 0.0 & 0.0 \\
\hline Serra Negra do Norte & & & & & & & & & & & & & \\
\hline Total & 48.5 & 27.2 & 31.2 & 31.1 & 6.0 & 6.2 & 15.5 & 3.0 & 0.0 & 78.4 & 18.2 & 21.4 & 16.7 \\
\hline \multicolumn{14}{|l|}{ Peridomicile } \\
\hline \multicolumn{14}{|l|}{ Apodi } \\
\hline corrals & 22.2 & 22.2 & 100 & 0.0 & 0.0 & 0.0 & 0.0 & 0.0 & 0.0 & 0.0 & 0.0 & 0.0 & 0.0 \\
\hline carnauba palm tree straw & 66.7 & 0.0 & 0.0 & 0.0 & 0.0 & 0.0 & 0.0 & 0.0 & 0.0 & 0.0 & 33.3 & 100.0 & 4.8 \\
\hline chicken coops & 13.3 & 13.3 & 100 & 0.0 & 0.0 & 0.0 & 0.0 & 0.0 & 0.0 & 0.0 & 0.0 & 0.0 & 0.0 \\
\hline piles of tiles & 20.0 & 20.0 & 100 & 22.7 & 0.0 & 0.0 & 0.0 & 0.0 & 0.0 & 0.0 & 0.0 & 0.0 & 0.0 \\
\hline \multicolumn{14}{|l|}{ Caicó } \\
\hline pigsties & 0.0 & 0.0 & 0.0 & 0.0 & 0.0 & 0.0 & 0.0 & 0.0 & 0.0 & 0.0 & 0.0 & 0.0 & 0.0 \\
\hline piles of tiles & 38.9 & 38.9 & 100.0 & 0.0 & 0.0 & 0.0 & 0.0 & 0.0 & 0.0 & 0.0 & 0.0 & 0.0 & 0.0 \\
\hline \multicolumn{14}{|l|}{ Governador Dix-Sept Rosado } \\
\hline chicken coops & 33.3 & 33.3 & 100.0 & 37.5 & 0.0 & 0.0 & 0.0 & 0.0 & 0.0 & 0.0 & 0.0 & 0.0 & 0.0 \\
\hline piles of tiles & 60.0 & 60.0 & 100.0 & 38.1 & 0.0 & 0.0 & 0.0 & 0.0 & 0.0 & 0.0 & 0.0 & 0.0 & 0.0 \\
\hline \multicolumn{14}{|l|}{ Lucrécia } \\
\hline chicken coops & 20.0 & 0.0 & 0.0 & 0.0 & 20.0 & 100.0 & 0.0 & 0.0 & 0.0 & 0.0 & 0.0 & 0.0 & 0.0 \\
\hline \multicolumn{14}{|l|}{ Mossoró } \\
\hline chicken coops & 0.0 & 0.0 & 0.0 & 0.0 & 0.0 & 0.0 & 0.0 & 0.0 & 0.0 & 0.0 & 0.0 & 0.0 & 0.0 \\
\hline \multicolumn{14}{|l|}{ São Miguel } \\
\hline chicken coops & 40.0 & 20.0 & 0.0 & 0.0 & 20.0 & 100.0 & 41.7 & 0.0 & 0.0 & 0.0 & 0.0 & 0.0 & 0.0 \\
\hline \multicolumn{14}{|l|}{ Serra Negra do Norte } \\
\hline chicken coops & 0.0 & 0.0 & 0.0 & 0.0 & 0.0 & 0.0 & 0.0 & 0.0 & 0.0 & 0.0 & 0.0 & 0.0 & 0.0 \\
\hline piles of tiles & 0.0 & 0.0 & 0.0 & 0.0 & 0.0 & 0.0 & 0.0 & 0.0 & 0.0 & 0.0 & 0.0 & 0.0 & 0.0 \\
\hline \multicolumn{14}{|l|}{ Severiano Melo } \\
\hline chicken coops & 57.1 & 42.8 & 0.0 & 0.0 & 14.3 & 33.3 & 0.0 & 0.0 & 0.0 & 0.0 & 0.0 & 0.0 & 0.0 \\
\hline Total & 33.7 & 26.2 & 73.0 & 19.2 & 5.9 & 15.9 & 27.1 & 0.0 & 0.0 & $\mathbf{0 . 0}$ & 0.5 & 1.6 & 4.5 \\
\hline
\end{tabular}


TABLE 2 - Continuation.

\begin{tabular}{|c|c|c|c|c|c|c|c|c|c|c|c|c|c|}
\hline Ecotopes & $\begin{array}{c}\text { Infested } \\
\text { ecotopes } \\
\%\end{array}$ & \multicolumn{3}{|c|}{$\begin{array}{c}\text { Triatoma } \\
\text { brasiliensis } \\
\%\end{array}$} & \multicolumn{3}{|c|}{$\begin{array}{c}\text { Triatoma } \\
\text { pseudomaculata } \\
\% \\
\end{array}$} & \multicolumn{3}{|c|}{$\begin{array}{c}\text { Panstrongylus } \\
\text { lutzi } \\
\% \\
\end{array}$} & \multicolumn{3}{|c|}{$\begin{array}{c}\text { Rhodnius } \\
\text { nasutus } \\
\% \\
\end{array}$} \\
\hline \multicolumn{14}{|l|}{ Intradomicile } \\
\hline Apodi & 0.0 & 0.0 & 0.0 & 0.0 & 0.0 & 0.0 & 0.0 & 0.0 & 0.0 & 0.0 & 0.0 & 0.0 & 0.0 \\
\hline Governador Dix-Sept Rosado & 0.0 & 0.0 & 0.0 & 0.0 & 0.0 & 0.0 & 0.0 & 0.0 & 0.0 & 0.0 & 0.0 & 0.0 & 0.0 \\
\hline Lucrécia & 0.0 & 0.0 & 0.0 & 0.0 & 0.0 & 0.0 & 0.0 & 0.0 & 0.0 & 0.0 & 0.0 & 0.0 & 0.0 \\
\hline Mossoró & 12.0 & 12.0 & 0.0 & 50.0 & 0.0 & 0.0 & 0.0 & 0.0 & 0.0 & 0.0 & 0.0 & 0.0 & 0.0 \\
\hline São Miguel & 0.0 & 0.0 & 0.0 & 0.0 & 0.0 & 0.0 & 0.0 & 0.0 & 0.0 & 0.0 & 0.0 & 0.0 & 0.0 \\
\hline Serra Negra do Norte & 18.7 & 18.7 & 0.0 & 33.3 & 0.0 & 0.0 & 0.0 & 0.0 & 0.0 & 0.0 & 0.0 & 0.0 & 0.0 \\
\hline
\end{tabular}

II: infestation index; CI: colonization index; NII: natural infection index.

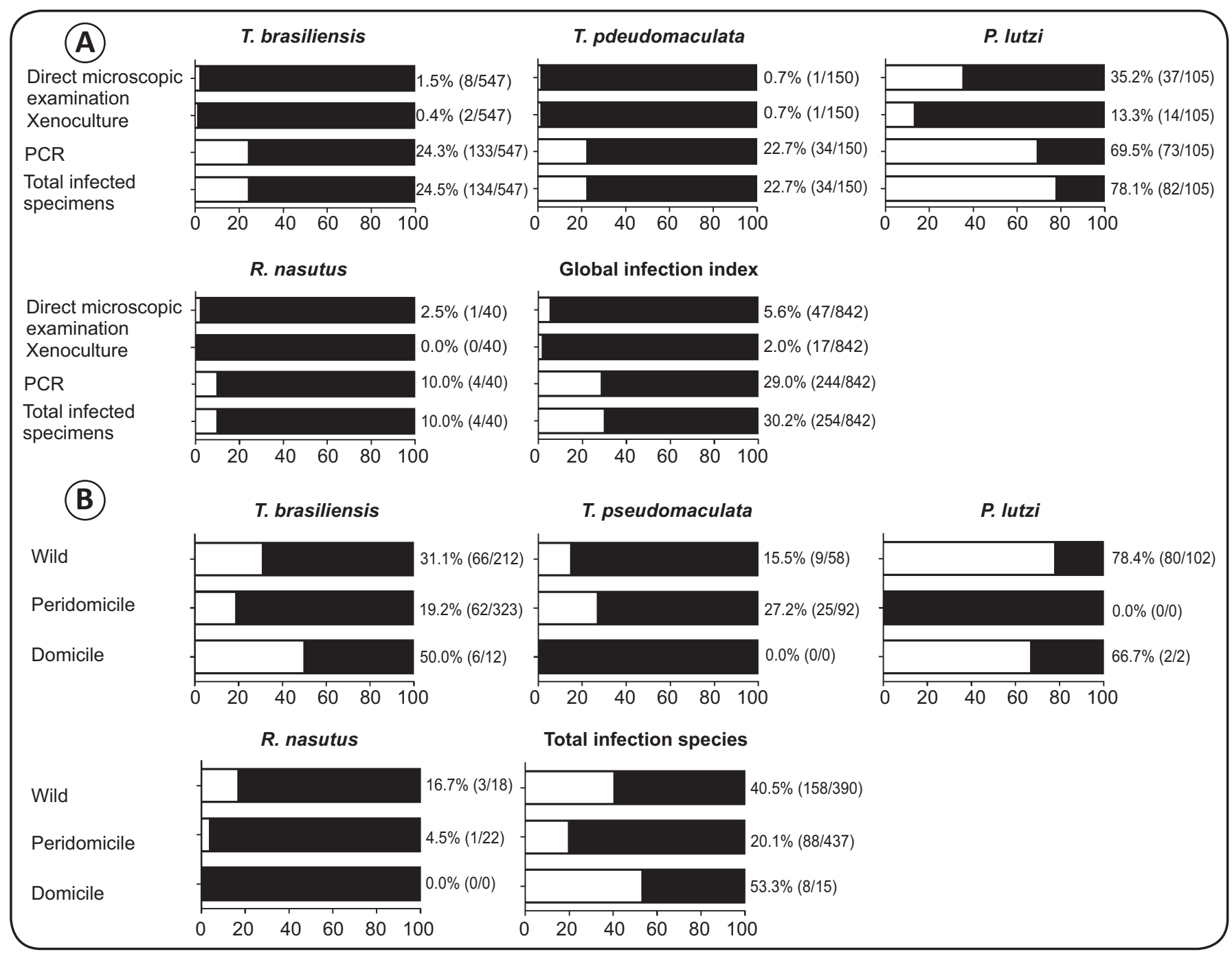

FIGURE 2 - Rate of natural infection of triatomine species by Trypanosoma cruzi as determined using different methods and in three distinct environments. A) Infection rate of triatomine species by detection method and global infection index. B) Infection rate of triatomines in different capture environments and total number of infected specimens. T. brasiliensis: Triatoma brasiliensis; T. pseudomaculata: Triatoma pseudomaculata; P. lutzi: Panstrongylus lutzi; $\boldsymbol{R}$. nasutus: Rhodnius nasutus; PCR: polymerase chain reaction. 
TABLE 3 - Geographical origin, development stage, environment, and genetic typing of Trypanosoma cruzi stocks from triatomine species.

\begin{tabular}{|c|c|c|c|c|c|}
\hline Trypanosoma cruzi stocks & Triatomine species & Stage & Environment & DTU & Municipality \\
\hline RN01 & Triatoma brasiliensis & nymph & peridomiciliary & TcII & Caicó \\
\hline RN02 & Triatoma brasiliensis & adult & wild & TcIII & Serra Negra do Norte \\
\hline RN03 & Triatoma brasiliensis & adult & wild & TcII & Serra Negra do Norte \\
\hline RN04 & Triatoma brasiliensis & nymph & wild & TcIII & Serra Negra do Norte \\
\hline RN07 & Panstrongylus lutzi & adult & wild & TcIII & Serra Negra do Norte \\
\hline RN08 & Panstrongylus lutzi & adult & wild & TcIII & Serra Negra do Norte \\
\hline RN09 & Panstrongylus lutzi & adult & wild & TcIII & Serra Negra do Norte \\
\hline RN18 & Panstrongylus lutzi & adult & intradomiciliary & TcIII & Caraúbas \\
\hline RN19 & Panstrongylus lutzi & adult & intradomiciliary & TcIII & Caraúbas \\
\hline RN213 & Panstrongylus lutzi & adult & wild & TcIII & Serra Negra do Norte \\
\hline RN812 & Panstrongylus lutzi & adult & wild & TcIII & Serra Negra do Norte \\
\hline Col1.7G2*(47) & human & - & - & TcI & - \\
\hline $\mathrm{JG}^{*(44)}$ & human & - & - & TcII & - \\
\hline $\mathrm{RN} 19 *(15)$ & human & - & - & TcIII & - \\
\hline
\end{tabular}

DTU: discrete typing units: TcI, TcII, TcIII, TcIV, TcV and TcVI. *T. cruzi strains and clones used as reference; 3253: Lages-Silva et al. (unpublished data).

\section{DISCUSSION}

This general assessment of triatomine occurrence demonstrated that the species T. brasiliensis, T. pseudomaculata, $P$. lutzi, and R. nasutus continue to exist in artificial environments in RN State municipalities, where they have been registered since the $1950 \mathbf{s}^{(7)(8)(14)(15)(51)(52)}$ and where high seroprevalence of human T. cruzi infection has been estimated ${ }^{(28)}$. The presence of other triatomine species has also been reported ${ }^{(5)(7)(8)(52)}$, but these were not found in this study.

Triatoma brasiliensis and Triatoma pseudomaculata were found in most municipalities as expected, being the main species caught in the semiarid $\mathrm{RN}$ region. $R$. nasutus was captured only in Apodi, Caraúbas, and Caicó municipalities and $P$. lutzi was found only in Serra Negra do Norte and in Caraúbas, as described ${ }^{(51)}$. In agreement with our studies, $T$. brasiliensis was the most frequently identified species, followed by T. pseudomaculata and R. nasutus, as observed in several studies ${ }^{(9)(53)}$.
We identified $T$. brasiliensis in the wild environment, peridomicile, and intradomicile with high $T$. cruzi infection rates. This species has been reported as semi-domestic, since it is an autochthonous species capable of colonizing domiciles and the peridomicile ${ }^{(12)}$. It is highly dispersed and frequent owing to its eurytopic characteristics, is not hygrophilous, is able to withstand very high temperatures, and thus is acclimatized to the vast expanse of the Northeastern region ${ }^{(13)}$.

Despite the absence of intradomicile colonies, frequent adult $T$. brasiliensis invasions occur because of the proximity of the wild environment with DUs. Residential lighting attracts these insects ${ }^{(54)}$, potentially explaining their localized capture. Peridomicile colonization was observed by T. brasiliensis and T. pseudomaculata nymphs, most frequently in chicken coops where they develop dense colonies, facilitating intradomiciliary invasion. T. brasiliensis was also found in piles of tiles, corrals, and associated with domestic and synanthropic animals, according to municipality. This species strongly associates with native rodents, especially Galea spp., which thrive 
around rural dwellings in this state ${ }^{(55)}$. The epidemiological profile similarities among the municipalities studied suggest the need for interventions to prevent parasite transmission in this environment to domestic animals and humans.

Degradation of the natural wild vector habitat allows the bugs to move close to human habitations; such coexistence increases the probability of human infection ${ }^{(56)}$. In the wild, T. brasiliensis was mainly found colonizing rocky outcrops and stone fences. Its occurrence in Northeastern Brazil is associated with rock formation distribution ${ }^{(6)}$. However, this species can also be found in shrubby cacti co-occupied by native rodents in Ceará ${ }^{(57)}$.

Triatoma pseudomaculata is widely distributed in the wild and is considered to be difficult to control ${ }^{(5)}$. T. pseudomaculata is primarily associated with Caatinga and areas of the Cerrado in Brazil ${ }^{(58)}$, and is an arboricolous species ${ }^{(59)}$. Here, the natural habitat of T. pseudomaculata was identified as bird's nests, corroborating previous findings ${ }^{(32)}$.

In the study area, the natural $R$. nasutus habitat was the Carnauba palm, considered the major ecotope of this species ${ }^{(9)(60)}$. Colonization foci were observed in the peridomicile in dry carnauba straw used by the rural population to manufacture household items in Apodi. This can be explained by the proximity of palm trees with DUs that attract insects as previously described or by passive insect transport by residents living in carnauba extraction areas, where storing dry leaves in the peridomicile is common. In the State of Ceará, $R$. nasutus has been frequently found colonizing the peridomicile owing to the use of carnauba straw for chicken coop roof construction and household goods manufacture ${ }^{(9)(61)}$.

Panstrongylus lutzi was the most infected species in the intradomicile and wild environment. The former is worrying because of the T. cruzi transmission risk to domestic animals and humans and potential introduction of a new parasite genetic group into the transmission cycles, since this area is currently exclusively infected with DTU $\mathrm{III}^{(15)}$. P. lutzi has restricted distribution in areas of the semiarid northeast although it has wide geographical distribution and a high $T$. cruzi infection rate in the State of Pernambuco. Its domiciliation has occurred in the States of Ceara and Pernambuco ${ }^{(62)(63)}$. P. lutzi is found in hollow Auxemma oncocalyx trunks in Ceará ${ }^{(64)}$ and in armadillo burrows in the semiarid Caatinga in Bahia ${ }^{(59)}$. However, the $P$. lutzi natural habitat was not identified despite extensive searching in the wild environment of the Serido Ecological Station where most specimens were captured; thus, further studies are required ${ }^{(15)(51)}$.

Currently, vector transmission is considered residual by a few native and peridomestic species such as T. brasiliensis and T. pseudomaculata. There is also a risk of progressive domiciliation of certain species previously considered sylvatic such as $P$. lutzi and the possibility of human infection directly related to the parasite enzootic cycle ${ }^{(62)}$. P. lutzi holds relevance toward maintaining the peridomestic and domestic T. cruzi transmission cycles, the risk of invasion and eventual colonization therein, and the consequent parasite transmission to domestic animals and humans. These results highlight the increasing epidemiological importance of $P$. lutzi and indicate the continuing necessity of maintaining epidemiological surveillance against $T$. cruzi transmission in the study area.

Here, we reported a slight agreement among T. cruzi detection methods used to evaluate infection in triatomines, and the importance of its association to field studies. T. cruzi infection varied among triatomine species according to method with PCR showing high positivity whereas detection by DME in intestinal contents was low. However, higher infection rates were reported with flagellates morphologically similar to $T$. cruzi in Pernambuco ${ }^{(63)}$, and similar or higher triatomine infection rates have been reported between methods ${ }^{(19)}(23)$ (24) (25). High PCR positivity in relation to DME has been previously observed, indicating its utility for epidemiological studies ${ }^{(19)(23)(24)(65)}$. PCR can also directly detect $T$. cruzi vector infection thus improving triatomine evaluation and should be used to assess infection rates in dead insects ${ }^{(25)}$ owing to its higher relative degree of precision. Thus, PCR represents the best tool for parasite detection, confirming the majority of infections ascertained by DME and xenoculture. However, these remain useful as the combination of methods can contribute to monitoring $T$. cruzi in triatomines and enhance confidence regarding triatomine positivity.

The Trypanosoma cruzi DTUs identified in 15 isolates from triatomine bugs were TcII and TcIII in T. brasiliensis and TcIII in P. lutzi. Previous findings showed these DTUs circulating in these species in the semiarid zone of $\mathrm{RN}^{(15)(17)}$ and highlight the need to understand T. cruzi population distribution in this area. Naturally heterogeneous $T$. cruzi populations involving TcI, TcII, and TcIII circulate among humans and triatomines in three different municipalities without domicile colonization ${ }^{(17)}$, and high genetic similarities exist among $T$. cruzi populations circulating in different hosts, localities, and environments ${ }^{(16)}$. TcII was detected in the peridomicile in Caicó and in the wild in Serra Negra do Norte, indicating its participation in sylvatic and peridomestic cycles. The original primary host of TcII appears to be primates. Whereas its ecological niche has yet to be determined, isolates have been described from opossums in the Atlantic forest and from sylvatic primates, suggesting that such primates might be the primary original mammalian host $\mathrm{t}^{(6)}$. TcII has also been isolated from the armadillo Euphractus sexcintus in the Paraguayan Chaco ${ }^{(67)}$. This DTU has been shown as the primary cause of severe acute and chronic Chagas disease in the Atlantic Forest and central region of Brazil and represents the etiological disease agent in São Felipe in the State of Bahia, where the domestic vector is $P$. megistus ${ }^{(67)}$.

TcIII was isolated from T. brasiliensis in the wild environment and from $P$. lutzi captured in the domiciliary and wild environments of two different localities. TcIII is a poorly understood $T$. cruzi genetic group predominantly identified among wild cycles of parasite transmission infecting terrestrial mammals and triatomine vectors, but is also a potentially important emergent human disease agent ${ }^{\left({ }^{(6)}\right)}$. A few triatomine species have been described in sylvatic TcIII transmission such as Panstrongylus geniculatus Latreille, 1811, and Triatoma rubrovaria Blanchard, 1843, both mainly sylvatic vectors frequently associated with terrestrial ecotopes ${ }^{(69)}$. TcIII is found 
in a broad range of terrestrial mammals and its transmission may occur inside triatomine-infested burrows by both vectorial and oral routes ${ }^{(29)(70)}$. Overlapping geographic areas of TcIII and $\mathrm{TcI}$ isolates occur across South America, with shared wild mammals and vectors in terrestrial ecotopes ${ }^{(29)}$. TcIII in domestic transmission cycles, while intermittent ${ }^{(68)}$, implies a role as a human disease agent. Furthermore, TcIII may be under-reported in both domestic and sylvatic transmission cycles because some typing methodologies fail to distinguish between TcIV and TcIII ${ }^{(71)}$. The TcII and TcIII identified in this study corroborate previous findings and reinforce the need for constant epidemiological surveillance of $T$. brasiliensis and P. lutzi to prevent TcIII spread to the domestic cycle ${ }^{(15)}$.

TcI was not detected in triatomines in the studied area. However, most studies conducted in northeastern Brazil have isolated this DTU from T. brasiliensis and T. pseudomaculata, with most naturally infected $T$. brasiliensis isolates being $\mathrm{TcI}^{(72)}$. TcI has also been identified in T. pseudomaculata and $R$. nasutus in the peridomicile and natural environments of five State of Ceará peri-urban and urban localities ${ }^{(73)}$. Therein, high TcI and TcII infection rates were detected in peridomestic T. brasiliensis and T. pseudomaculata, respectively ${ }^{(74)}$. TcI has been most frequently identified in triatomines of the State of Mato Grosso do $\mathrm{Sul}^{(75)}$. The majority of isolates from humans, reservoirs, and vectors from Amazonia correspond to $\mathrm{TcI}^{(29)}$ and it has been detected in humans from State of $\mathrm{RN}^{(15)(16)}$, with recent isolates from patients with various clinical forms of Chagas disease ${ }^{(17)}$. T. cruzi genotypes isolated from triatomines can vary according to vector-specific physiology and ecological habitat ${ }^{(43)}$, highlighting the necessary to accurately identify TcI in triatomines.

Our results suggest that combining methodologies contributed to increased parasite detection and to identifying infection foci to precisely determine triatomine distribution. Despite low parasite detection via xenoculture and DME, these methods allow the isolation of $T$. cruzi for further study. Owing to high peridomestic ecotope infestation and high $T$. brasiliensis and $T$. pseudomaculata $T$. cruzi infection, we recommend efficient entomological surveillance programs to detect possible colonization. This study contributes to our knowledge of T. cruzi diagnosis and identification in field-collected triatomines, further demonstrating that $T$. cruzi II and III predominate in the study area and, with future research, are essential for vector control and human infection prevention.

\section{ACKNOWLEDGMENTS}

The authors would like to thank the Secretariat of State for Public Health of Rio Grande do Norte, represented by the health authorities and agents of the Municipal Secretaries of the West and Central mesoregions for their indispensable support of the survey field activities. The authors are also grateful to Adalberto Antonio Varela-Freire MSc (in memoriam) and Philip S.P. Badiz for critical reading and revision of the manuscript.

\section{CONFLICT OF INTEREST}

The authors declare that there is no conflict of interest.

\section{FINANCIAL SUPPORT}

This work was supported by research grants from the Conselho Nacional de Desenvolvimento Científico e Tecnológico MCT/CNPq number 472251/2010-4 (EC); MCTI/CNPq/MSSCTIE-Decit number 404056/2012-1 (LMCG); Programa Nacional de Incentivo à Parasitologia Básica/CAPES number 23038.005288/2011-48 (ACJC); research fellowships from the $\mathrm{CNPq}$ (LMCG and EC), and a scholarship from CAPES (ANBS).

\section{REFERENCES}

1. Galvão C, Paula AS. Sistemática e evolução dos vetores. In: Galvão C, editor. Vetores da doença de Chagas. Curitiba (PR): Sociedade Brasileira de Zoologia 2015. p. 26-31.

2. Zeledón R, Rabinovich JE. Chagas' disease: an ecological appraisal with special emphasis on its insect vectors. Annu Rev Entomol 1981; 26:101-133.

3. Deane LM. Animal reservoirs of Trypanosoma cruzi in Brazil. Rev Bras Malariol D Trop 1964; 16:27-48.

4. Coura JR, Borges-Pereira J. Chagas disease: 100 years after its discovery. A systemic review. Acta Trop 2010; 115:5-13.

5. Dias JCP, Machado EMM, Fernandes AL, Vinhaes MC. General situation and perspectives of Chagas disease in Northeastern region, Brazil. Cad Saude Publica 2000; 16:13-34.

6. Gurgel-Gonçalves R, Galvão C, Costa J, Peterson AT. Geographic distribution of Chagas disease vectors in Brazil based on ecological niche modeling. J Trop Med 2012; 2012:705326.

7. Silveira AC, Feitosa VR, Borges R. Distribuição de triatomíneos capturados no ambiente domiciliar, no período de 1975/1983, no Brasil. Rev Bras Malariol D Trop 1984; 36:15-312.

8. Costa J, Almeida CE, Dotson EM, Lins A, Vinhaes M, Silveira AC, et al. The epidemiologic importance of Triatoma brasiliensis as a Chagas disease vector in Brazil: a revision of domiciliary captures during 1993-1999. Mem Inst Oswaldo Cruz 2003; 98: 443-449.

9. Sarquis O, Borges-Pereira J, Mac Cord JR, Gomes TF, Cabello PH, Lima MM. Epidemiology of Chagas disease in Jaguaruana, Ceará, Brazil. I. Presence of triatomines and index of Trypanosoma cruzi infection in four localities of a rural area. Mem Inst Oswaldo Cruz 2004; 99:263-270.

10. Almeida CE, Pacheco RS, Haag K, Dupas S, Dotson EM, Costa J. Inferring from the $C y t B$ gene the Triatoma brasiliensis Neiva, 1911 (Hemiptera: Reduviidae: Triatominae) genetic structure and domiciliary infestation in the state of Paraíba, Brazil. Am J Trop Med Hyg 2008; 78:791-802.

11. Carbajal de la Fuente AL, Dias-Lima A, Lopes CM, Emperaire L, Walter A, Ferreira A, et al. Behavioral plasticity of Triatominae related to habitat selection in Northeast Brazil. J Med Entomol 2008; 45:14-19.

12. Forattini OP. Biogeography, origin, and distribution of triatominae domicile dispersal in Brazil. Rev Saude Publica 1980; 14:265-299. 
13. Alencar JE. História natural da doença de Chagas no Estado do Ceará, Imprensa Universitária, Fortaleza, CE, p. 341, 1987.

14. Silveira AC, Vinhaes MC. Chagas disease: the epidemiological and control aspects. Rev Soc Bras Med Trop 1998; 31:15-60.

15. Câmara ACJ, Varela-Freire AA, Valadares HMS, Macedo AM, D'Ávila DA, Machado CR, et al. Genetic analyses of Trypanosoma cruzi isolates from naturally infected triatomines and humans in northeastern Brazil. Acta Trop 2010; 115:205-211.

16. Câmara ACJ, Lages-Silva E, Sampaio GHF, D’Ávila DA, Chiari E, Galvão LMC. Homogeneity of Trypanosoma cruzi I, II, and III populations and the overlap of wild and domestic transmission cycles by Triatoma brasiliensis in northeastern Brazil. Parasitol Res 2013; 112:1543-1550.

17. Martins K, Andrade CM, Barbosa-Silva AN, Nascimento GB, Chiari E, Galvão LMC, et al. Trypanosoma cruzi III causing the indeterminate form of Chagas disease in a semi-arid region of Brazil. Int J Infect Dis 2015; 39:68-75.

18. Silveira AC. New challenges and the future of control. Rev Soc Bras Med Trop 2011; 44 (supl 2):122-124.

19. Shikanai-Yasuda MA, Ochs DE, Tolezano JE, Kirchhoff LV. Use of the polymerase chain reaction for detecting Trypanosoma cruzi in triatomine vectors. Trans R Soc Trop Med Hyg 1996; 90:649-651.

20. Botto-Mahan C, Ortiz S, Rozas M, Cattan PE, Solari A. DNA evidence of Trypanosoma cruzi in Chilean wild vector Mepraia spinolai (Hemiptera: Reduviidae). Mem Inst Oswaldo Cruz 2005; 100:237-239.

21. Moser DR, Kirchhoff LV, Donelson JE. Detection of Trypanosoma cruzi by DNA amplification using the polymerase chain reaction. J Clin Microbiol 1989; 27:1477-1482.

22. Russomando G, Rojas AA, Almiron M, Figueredo A, Ferreira ME, Morita K. Trypanosoma cruzi: polymerase chain reaction-based detection in dried feces of Triatoma infestans. Exp Parasitol 1996; 83:62-66.

23. Braz LMA, Raiz-Jr R, Amato-Neto V, Alárcon RS, Gakyia E, Okay TS. The detection of Trypanosoma cruzi in Triatoma infestans: comparison of a PCR-based assay with microscopical examination. Ann Trop Med Parasitol 2007; 101:461-465.

24. Pizarro JC, Lucero DE, Stevens L. PCR reveals significantly higher rates of Trypanosoma cruzi infection than microscopy in the Chagas vector, Triatoma infestans: High rates found in Chuquisaca, Bolivia. BMC Infect Dis 2007; 7:66-73.

25. Dorn PL, Engelke D, Rodas A, Rosales R, Melgar S, Brahney $\mathrm{B}$, et al. Utility of the polymerase chain reaction in detection of Trypanosoma cruzi in Guatemalan Chagas' disease vectors. Am J Trop Med Hyg 1999; 60:740-745.

26. Bronfen E, Rocha FSA, Machado GBN, Perillo MM, Romanha AJ, Chiari E. Isolation of Trypanosoma cruzi samples by xenodiagnosis and hemoculture from patients with chronic Chagas' disease. Mem Inst Oswaldo Cruz 1989; 84:237-240.

27. Breniére SF, Bosseno MF, Revollo S, Rivera MT, Carlier Y, Tibayrenc M. Direct identification of Trypanosoma cruzi natural clones in vectors and mammalian hosts by polymerase chain reaction amplification. Am J Trop Med Hyg 1992; 46:335-341.

28. Brito CRN, Sampaio GHF, Câmara ACJ, Nunes DF, Azevedo PRM, Chiari E, et al. Seroepidemiology of Trypanosoma cruzi infection in the semiarid rural zone of the State of Rio Grande do Norte, Brazil. Rev Soc Bras Med Trop 2012; 45:346-352.

29. Marcili A, Lima L, Valente VC, Valente SA, Batista JS, Junqueira ACV, et al. Comparative phylogeography of Trypanosoma cruzi TCIIc: New hosts, association with terrestrial ecotopes, and spatial clustering. Infect Genet Evol 2009; 9:1265-1274.
30. World Health Organization (WHO). Control of Chagas' Disease. Technical Report Series 811. Genebra: WHO; 1991.

31. Diotaiuti L, Dias JCP. Occurrence and biology of Rhodnius neglectus Lent, 1954 in palm trees of suburban areas of Belo Horizonte, Minas Gerais. Mem Inst Oswaldo Cruz 1984; 79:293-301.

32. Carcavallo RU, Rodríguez MEF, Salvatella R, Curto de Casas SI, Sherlock IS, Galvão C, et al. Habitats and related fauna. In: Carcavallo RU, Galindéz-Girón I, Jurberg J, Lent H, editors. Atlas of Chagas Disease Vectors in the Americas. Vol II Rio de Janeiro (RJ): FIOCRUZ; 1998. p. 561-600.

33. Camargo EP. Growth and differentiation in Trypanosoma cruzi. I - Origin of metacyclic trypanosomes in liquid media. Rev Inst Med Trop 1964; 6:93-100.

34. Gomes ML, Macedo AM, Vago AR, Pena SDJ, Galvão LMC, Chiari E. Trypanosoma cruzi: optimization of polymerase chain reaction for detection in human blood. Exp Parasitol 1998; 88:2833.

35. Ávila HA, Sigman DS, Cohen LM, Millikan RC, Simpson L. Polymerase chain reaction amplification of Trypanosoma cruzi kinetoplast minicircle DNA isolated from whole blood lysates: diagnosis of chronic Chagas' disease. Mol Biochem Parasitol 1991; 48:211-222.

36. Degrave W, Fragoso SP, Britto C, Van Heuverswyn H, Kidane GZ, Cardoso MAB, et al. Peculiar sequence organization of kinetoplast DNA minicircles from Trypanosoma cruzi. Mol Biochem Parasitol 1988; 27:63-70.

37. Souto RP, Vargas N, Zingales B. Trypanosoma rangeli: discrimination from Trypanosoma cruzi based on a variable domain from the large subunit ribosomal RNA gene. Exp Parasitol 1999; 91:306-314.

38. Macedo AM, Martins MS, Chiari E, Pena SDJ. DNA fingerprinting of Trypanosoma cruzi: a new tool for characterization of strains and clones. Mol Biochem Parasitol 1992; 55:147-153.

39. D'Ávila DA, Macedo AM, Valadares HMS, Gontijo ED, Castro $\mathrm{AM}$, Machado CR, et al. Probing population dynamics of Trypanosoma cruzi during progression of the chronic phase in chagasic patients. J Clin Microbiol 2009; 47:1718-1725.

40. Souto RP, Zingales B. Sensitive detection and strain classification of Trypanosoma cruzi by amplification of a ribosomal RNA sequence. Mol Biochem Parasitol 1993; 62:45-52.

41. Freitas JM, Augusto-Pinto L, Pimenta JR, Bastos-Rodrigues L, Gonçalves VF, Teixeira SMR, et al. Ancestral genomes, sex, and the population structure of Trypanosoma cruzi. PLOS Pathog 2006; 2:e24.

42. Burgos JM, Altcheh J, Bisio M, Duffy T, Valadares HMS, Seidenstein ME, et al. Direct molecular profiling of minicircle signatures and lineages of Trypanosoma cruzi bloodstream populations causing congenital Chagas disease. Int J Parasitol 2007; 37:1319-1327.

43. Zingales B, Andrade SG, Briones MRS, Campbell DA, Chiari E, Fernandes O, et al. A new consensus for Trypanosoma cruzi intraspecific nomenclature: second revision meeting recommends TcI to TcVI. Mem Inst Oswaldo Cruz 2009; 104:1051-1054.

44. Lages-Silva E, Crema E, Ramírez LE, Macedo AM, Pena SDJ, Chiari E. Relationship between Trypanosoma cruzi and human chagasic megaesophagus: blood and tissue parasitism. Am J Trop Med Hyg 2001; 65:435-441.

45. Monteiro WM, Magalhães LKC, de Sá ARN, Gomes ML, Toledo MJO, Borges L, et al. Trypanosoma cruzi IV causing outbreaks of acute Chagas disease and infections by different haplotypes in the Western Brazilian Amazonia. PloS One 2012; 7:e41284. 
46. Zingales B, Pereira MES, Oliveira RP, Almeida KA, Umezawa ES, Souto RP, et al. Trypanosoma cruzi genome project: biological characteristics and molecular typing of clone CL Brener. Acta Trop 1997; 68:159-173.

47. Federici EE, Abelmann WH, Neva FA. Chronic and progressive myocarditis and myositis in $\mathrm{C} 3 \mathrm{H}$ mice infected with Trypanosoma cruzi. Am J Trop Med Hyg 1964; 13:272-280.

48. Santos FR, Pena SDJ, Epplen JT. Genetic and population study of a Y-linked tetranucleotide repeat DNA polymorphism with a simple non-isotopic technique. Hum Gene 1993; 90:655-656.

49. Fleiss JL, Levin B, Paik MC. Statistical Methods for Rates and Proportions. $3^{\text {rd }}$ ed. Hoboken: Wiley; 2003.

50. Landis JR, Koch GG. The measurement of observer agreement for categorical data. Biometrics 1977; 33:159-174.

51. Lucena DT. Doença de Chagas no Nordeste. Rev Bras Malariol D Trop 1959; 11:675-696.

52. Castro-Filho J, Silveira AC. Distribuição da Doença de Chagas no Brasil. Rev Bras Malariol D Trop 1979; 31:85-89.

53. Coutinho CFS, Souza-Santos R, Teixeira NFD, Georg I, Gomes $\mathrm{TF}$, Boia $\mathrm{MN}$, et al. An entomoepidemiological investigation of Chagas disease in the state of Ceará, Northeast Region of Brazil. Cad Saude Publica, 2014; 30:785-793.

54. Freitas SPC, Freitas ALC, Prazeres SM, Gonçalves TCM. Influence of anthropic habits in the dispersion of Triatoma pseudomaculata Corrêa \& Espínola, 1964 through Mimosa tenuiflora (Willdenow) (Mimosaceae) in the State of Ceará, Brazil. Cad Saude Publica 2004; 20:333-336.

55. Valença-Barbosa C, Lima MM, Sarquis O, Bezerra CM, FranchAbad F. Modeling disease vector occurrence when detection is imperfect II: Drivers of site-occupancy by synanthropic Triatoma brasiliensis in the Brazilian Northeast. PLoS Negl Trop Dis 2014a; 8:e2861.

56. Toledo MJO, Kühl JB, Silva SV, Gasperi V, Araújo SM. Biogeography, origin, and distribution of triatominae domiciliarity in Brazil. Rev Saude Publica 1997; 3:197-203.

57. Valença-Barbosa C, Lima MM, Sarquis O, Bezerra CM, AbadFranch F. Short report: A common Caatinga cactus, Pilosocereus gounellei, is an important ecotope of wild Triatoma brasiliensis population in the Jaguaribe Valley of Northeastern Brazil. Am J Trop Med Hyg 2014b; 90:1059-1062.

58. Carbajal de la Fuente AL, Porcasi X, Noireau F, Diotaiuti L, Gorla DE. The association between the geographic distribution of Triatoma pseudomaculata and Triatoma wygodzinskyi (Hemiptera: Reduviidae) with environmental variables recorded by remote sensors. Infect Genet Evol 2009; 9:54-61.

59. Dias-Lima AG, Menezes D, Sherlock I, Noireau F. Wild habitat and related fauna of Panstrongylus lutzi (Reduviidae, Triatominae). J Med Entomol 2003; 40:989-990.

60. Lima MM, Coutinho CFS, Gomes TF, Oliveira TG, Duarte R, Borges-Pereira J, et al. Risk presented by Copernicia prunifera palm trees in the Rhodnius nasutus distribution in a Chagas disease-endemic area of the Brazilian northeast. Am J Trop Med Hyg 2008; 79:750-754.

61. Sarquis O, Sposina R, Oliveira TG, Mac Cord JR, Cabello PH, Borges-Pereira $\mathrm{J}$, et al. Aspects of peridomiciliary ecotopes in rural areas of Northeastern Brazil associated to triatomine (Hemiptera, Reduviidae) infestation, vectors of Chagas disease. Mem Inst Oswaldo Cruz 2006; 101:143-147.
62. Silveira AC, Dias JCP. The control of vectorial transmission. Rev Soc Bras Med Trop 2011; 44:52-63.

63. Silva MBA, Barreto AVMS, Silva HA, Galvão C, Rocha D, Jurberg J, et al. Synanthropic triatomines (Hemiptera, Reduviidae) in the State of Pernambuco, Brazil: geographical distribution and natural Trypanosoma infection rates between 2006 and 2007. Rev Soc Bras Med Trop 2012; 45:60-65.

64. Garcia MHHM, Souza L, Souza RCM, Paula AS, Borges EC, Barbosa SE, et al. Occurrence and variability of Panstrongylus lutzi in the State of Ceará, Brazil. Rev Soc Bras Med Trop 2005; 38:410-415.

65. Cominetti MC, Almeida RFC, Gonçalves GMA, Andreotti R. Monitoring Trypanosoma cruzi infection in triatomines using PCR in Mato Grosso do Sul, Brazil. Rev Soc Bras Med Trop 2013; 46:277-280.

66. Lisboa $\mathrm{CV}$, Mangia RH, De Lima NRC, Martins A, Dietz J, Baker AJ, et al. Distinct patterns of Trypanosoma cruzi infection in Leontopithecus rosalia in distinct Atlantic coastal rainforest fragments in Rio de Janeiro - Brazil. Parasitology 2004; 129:703-711.

67. Miles MA, Llewellyn MS, Lewis MD, Yeo M, Baleela R, Fitzpatrick $\mathrm{S}$, et al. The molecular epidemiology and phylogeography of Trypanosoma cruzi and parallel research on Leishmania: looking back and to the future. Parasitology 2009; 136:1509-1528.

68. Llewellyn MS, Lewis MD, Acosta N, Yeo M, Carrasco HJ, Segovia M, et al. Trypanosoma cruzi IIc: phylogenetic and phylogeographic insights from sequence and microsatellite analysis and potential impact on emergent Chagas'disease. PLoS Negl Trop Dis 2009; 3:e510.

69. Gaunt M, Miles M. The ecotopes and evolution of triatomine bugs (Triatominae) and their associated trypanosomes. Mem Inst Oswaldo Cruz 2000; 95:557-565.

70. Yeo M, Acosta N, Llewellyn M, Sánchez H, Adamson S, Miles GA, et al. Origins of Chagas disease: Didelphis species are natural host of Trypanosoma cruzi I and armadillos hosts of Trypanosoma cruzi II, including hybrids. Int J Parasitol 2005; 35:225-233.

71. Fernandes O, Souto RP, Castro JA, Pereira JB, Fernandes NC, Junqueira ACV, et al. Brazilian isolates of Trypanosoma cruzi from humans and triatomines classified into two lineages using mini-exon and ribosomal RNA sequences. Am J Trop Med Hyg 1998; 58:807-811.

72. Pacheco RS, Brito CMM, Sarquis O, Pires MQ, Borges-Pereira J, Lima MM. Genetic heterogeneity in Trypanosoma cruzi strains from naturally infected triatomine vectors in northeastern Brazil: epidemiological implications. Biochem Genet 2005; 43:519-530.

73. Brito CMM, Lima MM, Sarquis O, Pires MQ, Coutinho CFS, Duarte R, et al. Genetic polymorphism in Trypanosoma cruzi I isolated from Brazilian Northeast triatomines revealed by lowstringency single specific primer-polymerase chain reaction. Parasitol Res 2008; 103:1111-1117.

74. Gumiel M, da Mota FF, Rizzo VS, Sarquis O, de Castro DP, Lima MM, et al. Characterization of the microbiota in the guts of Triatoma brasiliensis and Triatoma pseudomaculata infected by Trypanosoma cruzi in natural conditions using culture independent methods. Parasit Vectors 2015; 8:245.

75. Cominetti MC, Csordas BG, Cunha RC, Andreotti R. Geographical distribution of Trypanosoma cruzi in triatomine vectors in the State of Mato Grosso do Sul, Brazil. Rev Soc Bras Med Trop 2014; 47:747-755. 